\title{
The Effect of Silica Dissolution on Reservoir Properties during Alkaline-Surfactant-Polymer (ASP) Flooding
}

Ahmed Fatah ${ }^{\mathrm{a}, \mathrm{b}}$ *

a Department of Petroleum Engineering, Curtin University, Miri 98009, Malaysia.

b Faculty of Geoscience and Petroleum Engineering. Petroleum Engineering Department, Universiti Teknologi PETRONAS, 31750, Tronoh, Malaysia.

*Corresponding author, E-mail: a.fatah@postgrad.curtin.edu.my

ORCID: 0000-0003-4152-6060

\begin{abstract}
Chemical flooding is one of the effective methods to recover large volumes of oil from sandstone formations after primary depletion. However, silica dissolution often occurs during Alkaline-Surfactant-Polymer (ASP) flooding, affecting the petro-physical properties of the formation. To address this issue, samples from Berea sandstone formations were treated with various brine solutions, through static tube tests and core flooding experiments. Analytical tests such as DR/2800 spectrophotometer and scanning electron microscope were used to evaluate the silica solubility and the alteration in mineral content. The results indicated that the silicate contents decreased after the saturation due to silica solubility in the solution. Increasing brine salinity to 40,000ppm and introducing Magnesium and Calcium ions to the solution, reduces the silicate contents by $5.03 \%$ and $7.32 \%$. Moreover, saturating the samples with ASP solution, further reduced the silicate contents by $14.86 \%$. This reduction is associated with a relative increase in silica solubility and $\mathrm{pH}$ of the solution. Silica dissolution affects the pore microstructure, which resulted in increasing the porosity and pore volume after the core flooding. The injection of the ASP solution increased the porosity by $5.83 \%$, thus the pore volume increased from 17.72 to $18.76 \mathrm{cc}$. This is associated with the high silica solubility and the increase of solution $\mathrm{pH}$ in the ASP solution. The permeability of the samples generally reduced after the core flooding, due to the silica solubility. However, injecting the ASP solution, resulted in a major reduction of the permeability by more than $75 \%$. These changes in the petro-physical properties can lead to severe formation damage, and affect hydrocarbon production. This study assists in understanding the impact of silica dissolution during ASP treatment and addresses the factors involved. Efficient utilization of chemical flooding can help mitigating silicate scaling within the formation, and extend field productivity.
\end{abstract}

Keywords: Silica dissolution, Silica solubility, Chemical EOR, Porosity, Permeability 


\section{Introduction}

Oil and gas production are the primary energy sources for the world economy today (Cheng et al., 2020; Fatah et al., 2020). Primary, secondary, and tertiary recovery techniques are widely used to recover more hydrocarbon from depleted reservoirs (Jing et al., 2013). Enhanced oil recovery (EOR) is commonly applied method in sandstone reservoirs to improve oil production after secondary recovery (Jeirani et al., 2014). Alkaline-Surfactant-Polymer (ASP) flooding is an EOR method, that combines all the functions of the individual chemicals (Liu et al., 2020; Nguyen et al., 2014; Sonne, Kerr, et al., 2012). ASP flooding calls the EOR to the utmost, for its promising results in increasing oil recovery by $20 \%$ (K A Elraies et al., 2011; Li et al., 2014; Pratap \& Gauma, 2004; Yan et al., 2014). Surfactants are mainly used to reduce the water/oil interfacial tension (IFT), which leads to alter the wetting-phase and stabilize foam (Liu et al., 2020; Tagavifar et al., 2018). Polymers increase the solution viscosity and enhance its mobility ratio. This is crucial to achieving good sweep efficiency of the formation (Agi et al., 2018; Almahfood \& Bai, 2018). Alkaline increases the solution $\mathrm{pH}$, and forms the acrylic acid, which reduces the adsorption of the anionic surfactant and improves the performance of in situ surfactants (Liu et al., 2020).

Although chemical flooding was found effective in sandstone reservoirs, the issue of silicate scaling is causing severe problems to the production. The precipitation, accumulation, and deposition of silicate is a challenge to the wellbore stability and flow assurance of hydrocarbons (Jing et al., 2013; Lauren E. Beckingham, 2017). Other issues are related to the salinity and hardness of the ASP solution, which is found to increase the silica solubility at reservoir conditions (Ahmed \& Elraies, 2015). Sandstone reservoirs are mainly composed of quartz, which is the most stable form of amorphous silica in nature. Silicate scaling occurs when the concentration of the dissolved silica exceeds the solubility limit at a given temperature and $\mathrm{pH}$ (Bremere et al., 2000). However, the formation of silicate is highly complicated, involving silica dissolution, polymerization, and precipitation with other multivalent ions (Eq. 1, 2) (Amjad \& Zuhl, 2008; Arensdorf et al., 2010; Basbar et al., 2013; Gill, 1988; Iler, 1979; Sonne, Miner, et al., 2012). The water/silica interactions change the petro-physical properties of the formation through mineral dissolution, such as porosity and permeability (Tan et al., 2020). (Steinwinder \& Beckingham, 2019) reported that the mineral dissolution can significantly change the porosity and permeability of the wellbore. Moreover, several studies have found that silica dissolution is closely related to the $\mathrm{pH}$ of the solution, as the alkaline solutions are the main cause of dissolving high portions of silica ions due to the high $\mathrm{pH}$ (above 9) promoted around the wellbore, resulting in the dissolution of quartz (Ahmed \& Elraies, 2015; Arensdorf et al., 2010; Dobbs et al., 2019; A. K. Elraies et al., 2016). Also, the presence of $\mathrm{Ca}^{++}$and $\mathrm{Mg}^{++}$ions in the solution, accelerates the formation of silicate scale, due to the continuous polymerization of amorphous silica.

$$
\begin{array}{lr}
\mathrm{Si}(\mathrm{OH})_{4}+\mathbf{O H}^{-}=(\mathbf{O H})_{3} \mathrm{SiO}^{-}+\mathbf{H}_{2} \mathbf{O} & \text { Equation } 1 \\
\mathrm{Si}(\mathrm{OH})_{3}^{-}+\mathrm{Si}(\mathrm{OH})_{4}=(\mathbf{O H})_{3} \mathrm{Si}-\mathbf{O}-\mathrm{Si}(\mathbf{O H})_{3}+\mathbf{O H}^{-} & \text {Equation } 2
\end{array}
$$


Many ASP flooded oil reservoirs worldwide had experienced silica scaling problems that affect the productivity of the field. Several factors are directly involved in forming silicate scaling, and damaging the formation, such as brine salinity, ASP concentrations, $\mathrm{pH}$, and temperature (Ahmed \& Elraies, 2015; Ahmed et al., 2015; Basbar et al., 2013; Kazempour et al., 2012; Sonne, Kerr, et al., 2012). Injection of the alkaline solution in oil reservoir leads to mineral dissolution and precipitation, possibly resulting in changes in permeability and porosity, and consequently altering solution pH (Basbar et al., 2013; Kazempour et al., 2012). The alkaline solution causes two main changes in the reservoir; firstly, it affects the presented fluids by decreasing the mobility ratio causing emulsification. Secondly, it promotes a high $\mathrm{pH}$ environment, leading to dissolving minerals such as quartz, feldspar, and clays (Yupu et al., 2004). Several scholars have studied the formation of silicate scaling during water flood, confirming the possible reservoir damage caused by the precipitation of silica ions (Ikeda \& Ueda, 2017; Niu \& Zhang, 2019; Yanaze et al., 2019). A recent study by (Yanaze et al., 2019) reported a reduction in flow rates during water flooding accompanied by a significant reduction in permeability due to silica precipitation.

However, the impact of ASP solution on silicate scaling is not fully understood, and only limited studies have evaluated the implications of silica dissolution on reservoir properties during ASP flood. In this regard, this paper investigates the changes in porosity and permeability of Berea sandstone formation during ASP flooding. Static and core flooding experiments were employed to determine the silica solubility. Several analytical methods were used including field emission scanning electron microscopy (FESEM), energy dispersed X-ray (EDX), and DR/2800 spectrophotometer. The achieved results provide a good understanding of the behavior of silica dissolution during the ASP flood and its implications on reservoir properties.

\section{Methodology}

\subsection{Samples and Materials}

Core samples from Berea sandstone formations were used in this study and treated with various synthetic brine solutions, to evaluate the effect of silica dissolution on porosity and permeability during ASP injection. Samples were used as received from Kocurek Industries INC. Hard Rock Division (Caldwell, Texas), with no additional treatment. Core samples were prepared in various sizes to meet the test requirements. The bulk sample was crushed into powders, and then sieved into sizes of $(<75 \mu \mathrm{m})$ to fulfil the sampling requirements for silica solubility tests (Fatah, Ben Mahmud, et al., 2021). Fragments of the core sample were polished with 1500 silicon carbide grit, and cleaned with ethanol to be used for SEM analysis. This process ensures the removal of any contaminates after grinding (Fatah, Bennour, et al., 2021). Whole core plugs $(1.5 \times 3$ inches') were used for core flooding experiments. Then several samples were separated from the bulk powder, and saturated into various brine solutions as highlighted next. It should be noted that, all samples were preserved in polyethylene bags, to avoid oxidation. 
Sodium Chloride, Magnesium Chloride, and Calcium Chloride were used to prepare the brine solutions. While Sodium Metaborate, Alpha Olefin Sulfonate (AOS), and SH copolymer were used to prepare the ASP solution. All chemicals were used as received from the suppliers. Four synthetic brine solutions were used accordingly; 1) distilled water (DW), 2) 40,000 ppm synthetic brine, 3) 59,940ppm hard brine (Table 1), and 4) ASP solution with $0.8 \%$ alkali, $0.8 \%$ surfactant and 2000ppm copolymer concentrations (Figure 1). These solutions were prepared to mimic the injection scheme for ASP flooding in oil fields. DW and 40,000 ppm synthetic brine (prepared using $\mathrm{NaCl}$ only) were used to evaluate the impact of salinity. Magnesium Chloride and Calcium Chloride were used to prepare the 59,940ppm hard brine as suggested by (Ahmed \& Elraies, 2015). ASP solution was prepared based on the work of (K A Elraies \& Kalwar, 2013), who reported a high oil recovery percentage.

Table 1. Hard brine composition

\begin{tabular}{ccccc|c} 
Component & $\mathbf{N a}^{+}$ & $\mathbf{C a}^{++}$ & $\mathbf{M g}^{++}$ & $\mathbf{C l}^{-}$ & Total concentration \\
\hline Concentration (ppm) & 20,445 & 2523 & 239 & 36,733 & $\mathbf{5 9 , 9 4 0}$ \\
\hline
\end{tabular}
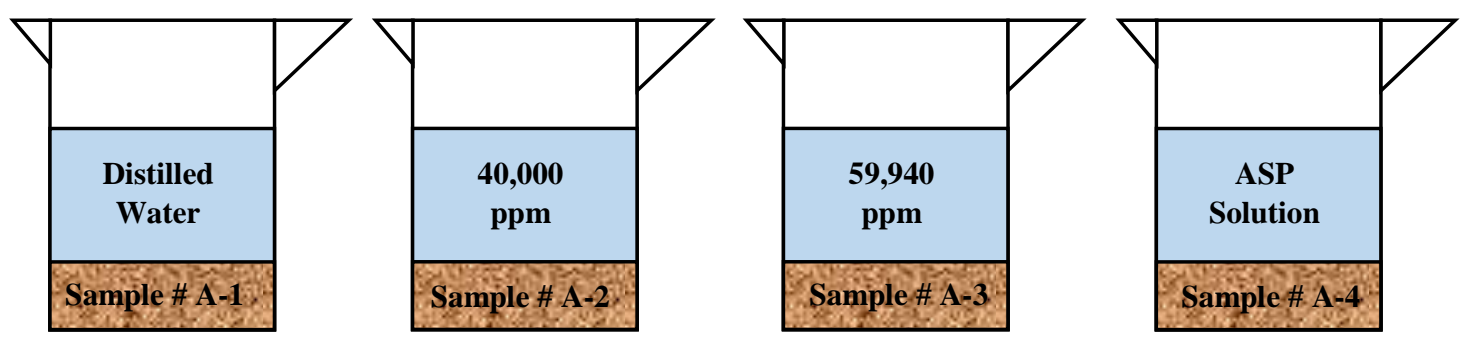

Figure 1. Schematic of crushed samples treatment in different brine solutions

\subsection{Experimental Design}

Three types of experiments were conducted in this study. 1) Static experiments; test tubes were used to saturate eight grams of the crushed core sample in $30 \mathrm{~mL}$ of synthetic brine for 3 days to achieve equilibrium (Figure 1). It should be mentioned that we assume that the silica/brine reaction rate is not affected by the fluid flow, and the surface area of the sample does not drop significantly as dissolution proceeds (Southwick, 1985). After equilibrium, silica solubility was detected in the brine solution. 2) Characterization tests; the alteration of silicate minerals was determined using Supra 55VP Zeiss Variable Pressure scanning electron microscope with energy dispersive spectrometer (SEM/EDX) before and after the saturation, at a resolution of $2 \mathrm{~nm}$ at $30 \mathrm{kV}$. Silica solubility was measured based on the Silicomolybdate method using DR/2800 Spectrophotometer at room temperature. This method allows us to detect silica concentration in solutions at high ranges in $(\mathrm{mg} / \mathrm{L})$.

3) Core flooding were performed using Benchtop Permeability System (BPS-805) at room temperature. The alteration in rock properties was evaluated using the PoroPerm system before and after flooding at $25^{\circ} \mathrm{C}$. Before the core flooding; samples were dried at $80^{\circ} \mathrm{C}$, and then saturated under a vacuum pump at ambient temperature with the synthetic brine for one day 
for sufficient saturation. The saturated core sample was placed in the core holder and the brine solution was injected at an injection rate of $0.2 \mathrm{cc} / \mathrm{min}$ until deferential pressure stabilized. The core sample was then removed from the chamber, dried, and evaluated again using the PoroPerm system. Moreover, silica solubility of the outlet solution was detected and compared with the static experiments.

\section{Results and Discussion}

\subsection{SEM/EDX Analysis}

The SEM images of the samples before and after saturation are shown in Figure 2. Quartz grains are the most dominant component in the samples and vary in appearance from subrounded to well-rounded grains. These grains are covered by a thin layer of amorphous silica cement, with spread micro-cracks. However, after treatment, various changes in the surface morphology were observed. Mainly, the silica film around the quartz grains was removed after saturation due to the dissolved silica into the solution. Several dark spots appeared after the saturation, and the grains' surface became more smooth.

The mineral element contents before and after the saturation are given in Table 2. The EDX analysis shows considerable changes in silicate contents after the saturation, which confirms the silica dissolution. Sample A-1 shows minor changes after saturating with DW, however, increasing the salinity to $40,000 \mathrm{ppm}$ has increased the silica dissolution in sample A-2. As a result, the silicate contents reduced by $5.03 \%$, due to the presence of $\mathrm{Cl}^{-}$ions in the solution, and increasing the degree of hydration. Introducing $\mathrm{Mg}^{2+}$ and $\mathrm{Ca}^{2+}$ ions to the brine in sample A-3, have further increased silica dissolution, and the silicate contents reduced by $7.32 \%$. This is related to the depletion of the silicic acid by $\mathrm{Mg}^{2+}$ and $\mathrm{Ca}^{2+}$ minerals, resulting in dissolving more silica (Basbar et al., 2013). Sample A-4 was treated with the ASP solution and indicated the highest reduction in silicate contents by $14.86 \%$. This is attributed mainly to the high $\mathrm{pH}$ environment created by the alkaline, which allows the brine to dissolve more silica. Besides the additional impact of surfactant in displacing water molecules from silica surface, thus increasing the silica dissolution.

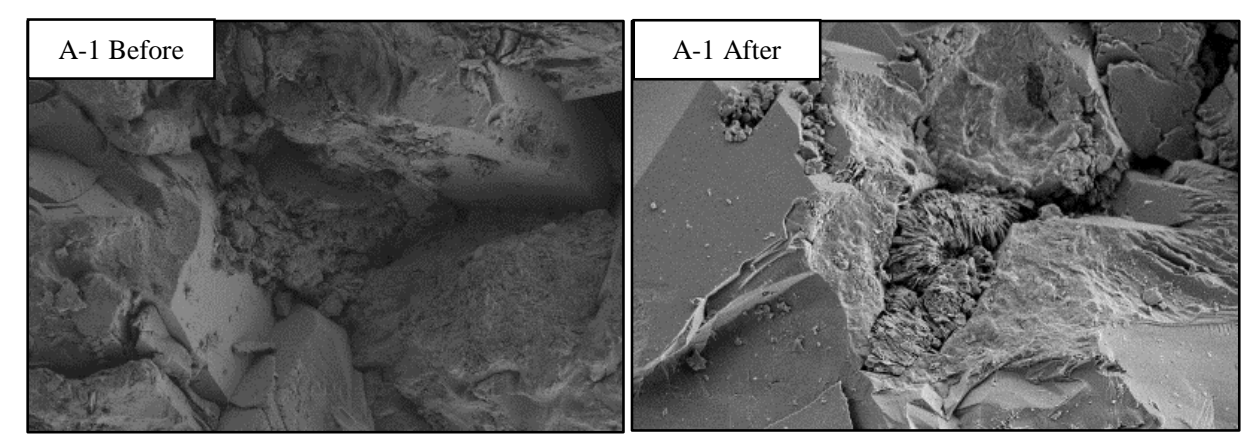



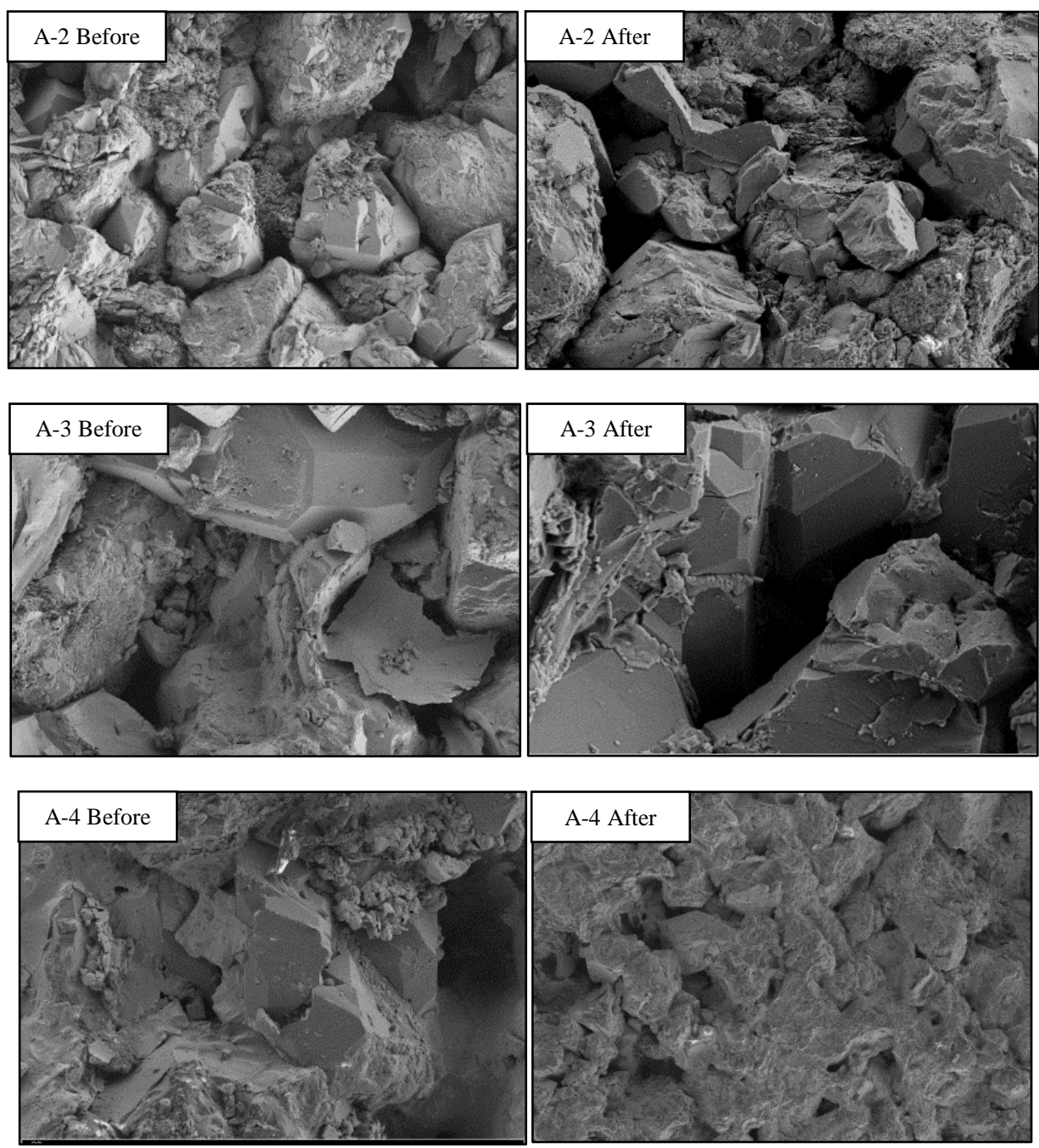

Figure 2. SEM images before and after saturation

Table 2. Mineral elements before and after the treatment

\begin{tabular}{|c|c|c|c|c|c|c|c|c|c|c|}
\hline \multirow{2}{*}{ Sample } & \multirow{2}{*}{$\begin{array}{c}\text { Synthetic } \\
\text { Brine }\end{array}$} & \multicolumn{7}{|c|}{ Mineral Element Content, (Atomic \%) } & \multirow{2}{*}{$\begin{array}{c}\text { Total } \\
\text { Silicate } \\
\text { Content \% }\end{array}$} & \multirow{2}{*}{ Reduction } \\
\hline & & & $\mathbf{O}$ & $\mathbf{S i}$ & Al & $\mathbf{C l}$ & $\mathbf{K}$ & Others* & & \\
\hline \multirow{2}{*}{ A-1 } & \multirow{2}{*}{ DW } & Before & 68.13 & 28.16 & 1.34 & - & 0.65 & 1.72 & 96.29 & \multirow{2}{*}{$0.51 \%$} \\
\hline & & After & 69.63 & 26.17 & 1.83 & - & 1.33 & 1.04 & 95.8 & \\
\hline \multirow{2}{*}{ A-2 } & \multirow{2}{*}{$40,000 \mathrm{ppm}$} & Before & 69.24 & 28.72 & 1.52 & - & 0.53 & 0 & 97.96 & \multirow{2}{*}{$5.03 \%$} \\
\hline & & After & 67.42 & 25.61 & 1.78 & 1.69 & 0.68 & 2.82 & 93.03 & \\
\hline \multirow{2}{*}{ A-3 } & \multirow{2}{*}{$59,940 \mathrm{ppm}$} & Before & 69.96 & 26.35 & 1.50 & 0.43 & 0.65 & 1.11 & 96.31 & \multirow{2}{*}{$7.32 \%$} \\
\hline & & After & 65.37 & 23.89 & 1.74 & 8.11 & 0.38 & 0.51 & 89.26 & \\
\hline \multirow{2}{*}{ A-4 } & \multirow{2}{*}{ ASP Solution } & Before & 69.72 & 26.61 & 1.44 & 0.83 & 1.40 & 0 & 96.33 & \multirow{2}{*}{$14.86 \%$} \\
\hline & & After & 58.40 & 23.62 & - & 8.37 & - & 9.61 & 82.02 & \\
\hline
\end{tabular}

* Others includes $\mathrm{Ca}, \mathrm{S}, \mathrm{Fe}$, and $\mathrm{Na}$

\subsection{Silica Solubility Measurements}


Table 3 presents the silica solubility results for the treated samples with different synthetic brine solutions. In the static tests, crushed core samples indicated relatively higher silica solubility than the core chips. This is related to the size of the grain particles and the surface area, as the small grain particles are more soluble in brine. Saturating sample A-1 in DW indicated a solubility of $4.5 \mathrm{mg} / \mathrm{L}$. The silica solubility increased to $8.3 \mathrm{mg} / \mathrm{L}$ when the brine salinity increased to $40,000 \mathrm{ppm}$ for sample A-2. This is attributed to the effect of the degree of hydration. When the crystalline silica grains are contacted with the brine, they contain the water inside the crystals, which is known as the water of hydration. The amount of this water decreases with the increasing salt contents, thus the high hydrated particles have low silica solubility which has low salt contents. At the presence of $\mathrm{Mg}^{2+}$ and $\mathrm{Ca}^{2+}$ ions, the silica dissolution increased to $15.5 \mathrm{mg} / \mathrm{L}$, meanwhile, the increase of $\mathrm{pH}$ to 8.3 , contributed to dissolving more silica from sample A-3.

Saturating sample A-4 in the ASP solution indicated a high silica solubility value of $48.2 \mathrm{mg} / \mathrm{L}$. The significant increase in the solution $\mathrm{pH}$ above 9 , makes the silica more soluble (Bowman et al., 2000). This increase in the $\mathrm{pH}$ leads to depleting the silicic acid, and enforces the system to re-equilibrate, resulting in dissolving additional silica. The measured silica dissolution from the core flooding experiments is aligned with the static tests. However, the measured value of soluble silica at the outlet solution is relatively higher than the corresponding amount during the static test. This is related to the equilibrium time, as the flooded core samples require more time to reach the equilibrium conditions, thus more silica is dissolved. Besides the continuous fluid flow in the flooded core sample ensures covering more surface area, compared to the static tests. In summary, silica solubility is highly affected by the brine salinity and the presence of hard minerals. During the ASP flood, the high $\mathrm{pH}$ environment created by the alkaline contributes to dissolve more silicate minerals, which can affect the reservoir properties and hydrocarbon production.

Table 3. Silica solubility measurement at $25^{\circ} \mathrm{C}$

\begin{tabular}{c|c|c|c|c} 
& \multicolumn{3}{c}{ Silica Dissolution, mg/L } & \\
\cline { 2 - 4 } Sample & \multicolumn{2}{c|}{ Static Experiments } & $\begin{array}{c}\text { Core Flooding } \\
\text { Experiment }\end{array}$ & \multirow{2}{*}{ pH } \\
\cline { 2 - 4 } & Crushed & Chips & Cores & \\
\hline A-1 & 4.5 & 3.7 & 4.5 & 7 \\
A-2 & 8.3 & 6.1 & 15.5 & 8 \\
A-3 & 15.5 & 6.4 & 20.5 & 8.3 \\
A-4 & 48.2 & 25.2 & 28.4 & 9.9 \\
\hline
\end{tabular}

\subsection{The Effect of Silica Dissolution on Porosity and Pore Volume}

Table 4 shows the alteration of porosity and pore volume after core flooding experiments by Poroperm. The presented results in Table 4 indicated that the porosity and pore volume increased after the core flooding, due to silica solubility. These results support the earlier findings from the static tests and confirm the impact of silica dissolution on the core's 
properties. The dissolved amount of the silica had minor increases in the porosity of sample A1 from $21.89 \%$ to $22.13 \%$, an increase of $1.1 \%$. The corresponding pore volume increased as well from 18.61 to $18.82 \mathrm{cc}$. Injecting saline brine with the presence of $\mathrm{Mg}^{2+}$ and $\mathrm{Ca}^{2+}$ minerals further increase the silica solubility. Thus the porosity of samples A-2 and A-3 increased by $1.13 \%$ and $3.22 \%$ respectively, accompanied by an increase in the pore volumes. Moreover, the injection of the ASP solution increased the porosity of sample A-4 by $5.83 \%$, and subsequently, the pore volume increased from 17.72 to $18.76 \mathrm{cc}$. This increase is caused by the high amount of dissolved silica and $\mathrm{pH}$ value in the ASP solution. These findings are in agreement with the obtained results from static experiments and confirms that silica solubility can alter the porosity and the pore volume of the reservoir. These findings can assist in designing ASP flooding treatments, by considering the influence of silica dissolution.

Table 4. Porosity and pore volume (PV) before and after core flooding

\begin{tabular}{|c|c|c|c|c|c|}
\hline \multicolumn{2}{|c|}{ Sample } & \multirow{3}{*}{$\begin{array}{c}\text { PV, cc } \\
18.61 \\
18.82\end{array}$} & \multirow{3}{*}{$\frac{\text { PV Increase \% }}{1.13}$} & \multirow{3}{*}{$\begin{array}{c}\text { Porosity, \% } \\
21.89 \\
22.13\end{array}$} & \multirow{3}{*}{$\frac{\text { Porosity Increase \% }}{1.10}$} \\
\hline \multirow{2}{*}{ A-1 } & Before & & & & \\
\hline & After & & & & \\
\hline \multirow{2}{*}{ A-2 } & Before & 15.86 & \multirow{2}{*}{1.07} & 18.53 & \multirow{2}{*}{1.13} \\
\hline & After & 16.03 & & 18.74 & \\
\hline \multirow{2}{*}{ A-3 } & Before & 17.2 & \multirow{2}{*}{3.14} & 19.88 & \multirow{2}{*}{3.22} \\
\hline & After & 17.74 & & 20.52 & \\
\hline \multirow{2}{*}{ A-4 } & Before & 17.72 & \multirow{2}{*}{5.87} & 20.59 & \multirow{2}{*}{5.83} \\
\hline & After & 18.76 & & 21.79 & \\
\hline
\end{tabular}

\subsection{The Effect of Silica Dissolution on Permeability}

The effect of silica dissolution on cores' permeability was determined by two methods. 1) analyzing the changes in the injected pore volume (IPV) with the pressure difference during the flooding experiment (BPS-805), and 2) using PoroPerm on the dried sample after the flooding test. For the first method, the pressure readings were recorded every 10 minutes, and the corresponding IPV values were calculated based on the equivalent flow rate and porosity. The permeability values were calculated based on Darcy's Law and compared with the obtained results from the PoroPerm test. Table 5 shows the obtained results for permeability alteration after the core flooding experiments for both methods. Before the core flooding experiment, each sample was flooded with a deionized brine solution to acquire the initial value of the core's permeability.

Table 5. Permeability of the core samples before and after core flooding

\begin{tabular}{|c|c|c|c|c|c|}
\hline \multirow{2}{*}{\multicolumn{2}{|c|}{ Sample }} & \multicolumn{2}{|c|}{ PoroPerm } & \multicolumn{2}{|c|}{ Core Flooding (BPS-805) } \\
\hline & & $\begin{array}{c}\text { Permeability, } \\
\text { mD }\end{array}$ & $\begin{array}{l}\text { Permeability } \\
\text { Reduction \% }\end{array}$ & $\begin{array}{c}\text { Permeability, } \\
\text { mD }\end{array}$ & $\begin{array}{l}\text { Permeability } \\
\text { Reduction \% }\end{array}$ \\
\hline A-1 & $\begin{array}{l}\text { Before } \\
\text { After }\end{array}$ & $\begin{array}{l}194.50 \\
165.53\end{array}$ & $14.89 \%$ & $\begin{array}{l}3.56 \\
3.49\end{array}$ & $1.97 \%$ \\
\hline A-2 & $\begin{array}{l}\text { Before } \\
\text { After }\end{array}$ & $\begin{array}{c}101.09 \\
82.53 \\
\end{array}$ & $18.36 \%$ & $\begin{array}{l}55.74 \\
32.23\end{array}$ & $42.18 \%$ \\
\hline$\overline{A-3}$ & Before & 156.17 & $39.53 \%$ & 17.18 & $47.79 \%$ \\
\hline
\end{tabular}




\begin{tabular}{cccccc} 
& After & 94.44 & & 8.97 & \\
\hline \multirow{2}{*}{ A-4 } & Before & 192.62 & \multirow{2}{*}{$41.84 \%$} & $\begin{array}{c}131.68 \\
31.57\end{array}$ & $76.03 \%$ \\
& After & 112.02 & & \\
\hline
\end{tabular}

Figure 3 illustrates the relationship between the IPV and the pressure for all samples during the flooding experiment. The pressure difference in sample A-1 started to stabilize at 10psig after injecting around 2PV of brine solution. However, around 3PV of DW was injected to stabilize the pressure at $11 \mathrm{psig}$. The low difference in pressure stabilization value indicates a minor reduction in permeability by $2 \%$. The pressure difference of sample A-2 relatively increased when flooded with the 40,000ppm brine. Around 1PV was enough for the pressure to stabilize when the sample was flooded with the brine, while more than $2.5 \mathrm{PV}$ of $40,000 \mathrm{ppm}$ brine was injected for the pressure to stabilize. This results in a significant reduction of the permeability from $55.74 \mathrm{mD}$ to $32.23 \mathrm{mD}$, a reduction of $42.18 \%$. Similarly, sample A-3 indicated a permeability reduction of $47.79 \%$, resulted from injecting hard brine solution to the sample. Based on the results in Figure 3, the early stages of the flooding showed no significant reduction in permeability value. However, after the injection of $2 \mathrm{PV}$, the pressure continued to increase and stabilized at 5psig, after 3PV of the hard brine was injected. The injection of ASP solution indicated a major reduction in the permeability of sample A-4. The permeability reduced from 131.68 to $31.57 \mathrm{mD}$, a reduction of more than $75 \%$. Injecting brine solution to sample A-4, stabilized the pressure at $2 \mathrm{psig}$ after injecting $0.5 \mathrm{PV}$. However, the pressure stabilized at $4.5 \mathrm{psig}$ after injecting $2.5 \mathrm{PV}$ of the ASP solution, which led to a significant reduction in the permeability.

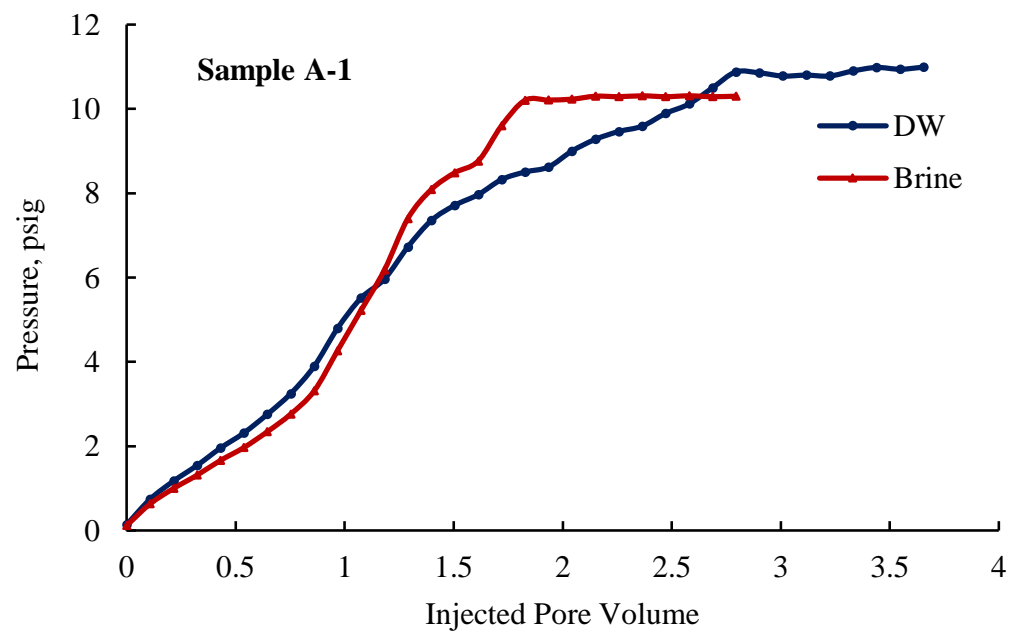



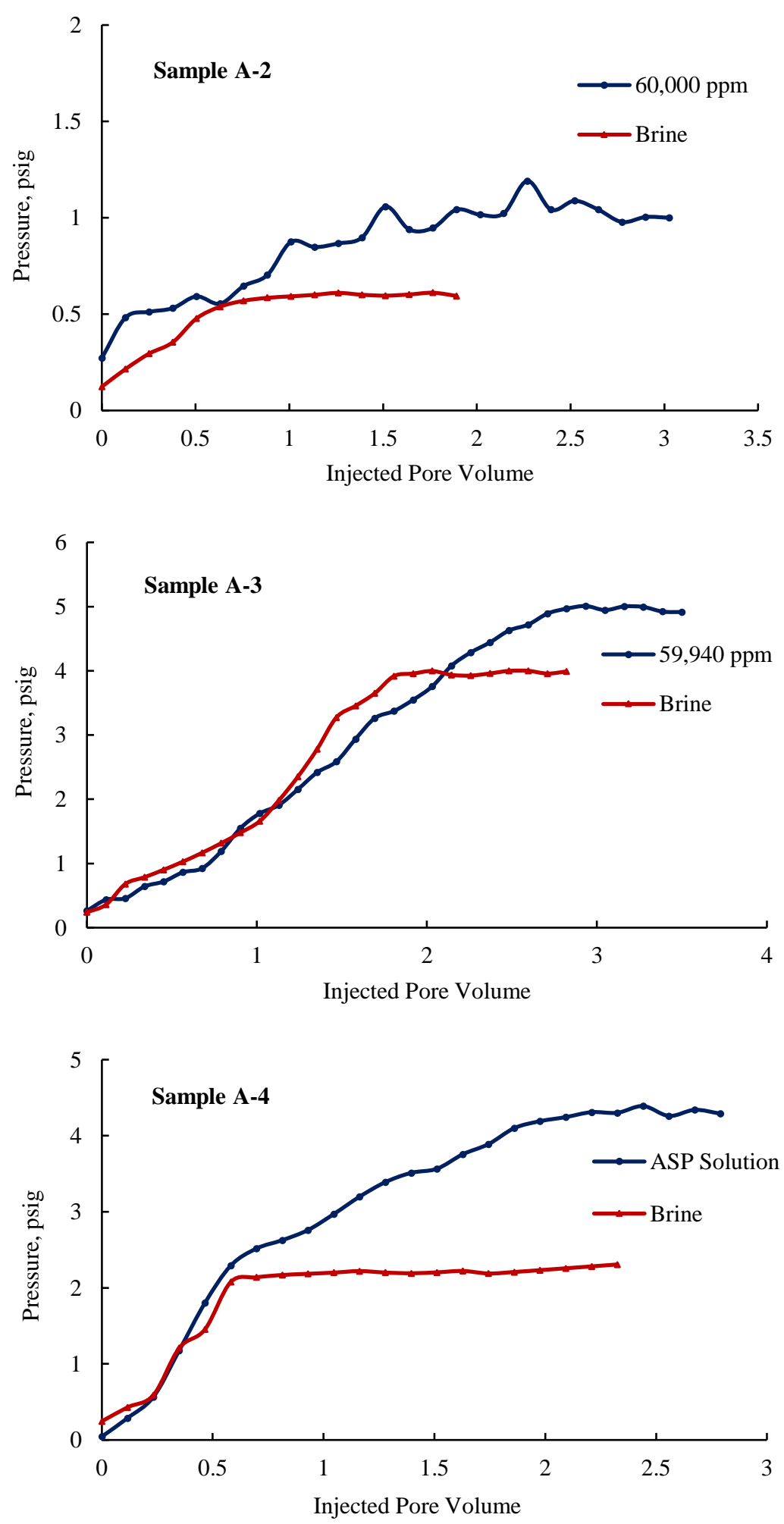

Figure 3. The relationship between Injected Pore Volume and Pressure during core flooding, at $25^{\circ} \mathrm{C}$

Based on the obtained results, the injection of ASP solution resulted in a major reduction of permeability, due to the massive precipitation of the soluble silica within the porous media. However, there is a noticeable difference in the permeability values acquired by the PoroPerm 
system and the brine injection method (Table 5). Normally, the brine permeability is consistently lower than the gas permeability, as the gas measurements are carried out on a dry core sample, while the brine measurements are performed on saturated samples. Some empirical relationships were developed to relate the gas permeability values to the brine permeability values (Swanson, 1981). Nevertheless, both methods confirm the high reduction of permeability associated with injecting ASP solution.

The changes in the core's properties increase the risk of damaging the wellbore of an ASP flooded well and affect the production of hydrocarbons. Therefore, successful designing of ASP treatment can mitigate the impact of silicate scaling within the formation, and extend the production lifecycle. This study investigated some factors that have a significant effect on silica dissolution in sandstone formations. By controlling these factors, silicate scaling can be delayed, mitigated, or inhibited at early stages, to ensure a longer lifetime for the field productivity.

\section{Conclusion}

In this paper, samples from Berea sandstone formation were used to investigate the effect of silica dissolution on porosity and permeability during ASP flood. Core flooding and static tests showed that the silicate contents decreased after the saturation, associated with a relative increase in silica solubility and $\mathrm{pH}$ of the solution. Increasing brine salinity and hardness increases the soluble silica in the solution, due to the depletion of the silicic acid by $\mathrm{Mg}^{2+}$ and $\mathrm{Ca}^{2+}$ minerals. Moreover, the injection of the ASP solution indicated a relatively high silica solubility of $48.2 \mathrm{mg} / \mathrm{L}$, with a reduction in silicate contents by $14.86 \%$. This reduction is related to the high $\mathrm{pH}$ environment created by the alkaline solution. The pore microstructure properties were altered after the injection of the ASP solution. The pore volume increased from 17.72 to $18.76 \mathrm{cc}$ after the core flooding experiment, thus the porosity increased by $5.83 \%$. this is directly related to the high silica solubility and the increase of solution $\mathrm{pH}$ in the ASP solution. Furthermore, the permeability of the samples generally reduced after the core flooding experiment, due to the impact of silica dissolution. A significant reduction by $75 \%$ occurred with the injection of the ASP solution. Silica dissolution is one of the critical factors that affect production wells and leads to severe formation damage. Therefore, addressing the effect of silica dissolution on the petro-physical properties of sandstone formations is crucial for effective chemical flood treatment. The achieved results in this study assist in understanding the silica solubility behavior, and the factors involved. Which can help to mitigate silicate scaling, and extend field productivity.

\section{Notes}

The author declares no competing financial interest. 


\section{References}

Agi, A., Junin, R., \& Gbadamosi, A. (2018). Mechanism governing nanoparticle flow behaviour in porous media: insight for enhanced oil recovery applications. International Nano Letters, 8(2), 49-77. https://doi.org/10.1007/s40089-0180237-3

Ahmed, F. A., \& Elraies, A. K. (2015). The Effect of Water Salinity and Reservoir Temperature on Silica Dissolution During ASP Flood: Static Model. In M. Awang, B. M. Negash, N. A. Md Akhir, \& L. A. Lubis (Eds.), ICIPEG 2014 (pp. 99-107). https://doi.org/10.1007/978-981-287-368-2_9

Ahmed, F. A., Elraies, A. K., Mohammed, A. A., \& Gaafar, R. G. (2015). An investigation study on the effect of brine composition on silica dissolution. Advances in Environmental and Geological Science and Engineering, 188-192.

Almahfood, M., \& Bai, B. (2018). The synergistic effects of nanoparticle-surfactant nanofluids in EOR applications. Journal of Petroleum Science and Engineering, 171(July), 196-210. https://doi.org/10.1016/j.petrol.2018.07.030

Amjad, Z., \& Zuhl, R. W. (2008). An Evaluation of Silica Scale Controle Additives for Industrial Water Systems. NACE 08368 .

Arensdorf, J., Hoster, D., Mcdougall, D., \& Yuan, M. (2010). Static and Dynamic Testing of Silicate Scale Inhibitors. SPE 132212.

Basbar, A. E. A., Elraies, K. A., \& Osgouei, R. E. (2013). Formation Silicate Scale Inhibition during Alkaline Flooding: Static Model. SPE 164669.

Bowman, R. W., Gramms, L. C., \& Craycraft, R. R. (2000). High-Silica Waters in Steamflood Operations. SPE 63015.

Bremere, I., Kennedy, M., Mhyio, S., Jaljuli, A., Witkamp, G., \& Schippers, J. (2000). Prevention of silica scale in membrane systems : removal of monomer and polymer silica. ELSEVIER, 132(October), 89-100.

Cheng, Y., Zeng, M., Lu, Z., Du, X., Yin, H., \& Yang, L. (2020). Effects of supercritical CO2 treatment temperatures on mineral composition, pore structure and functional groups of shale: Implications for $\mathrm{CO} 2$ sequestration. Sustainability (Switzerland), 12(9). https://doi.org/10.3390/su12093927

Dobbs, H. A., Degen, G. D., Berkson, Z. J., Kristiansen, K., Schrader, A. M., Oey, T., ... Israelachvili, J. N. (2019). Electrochemically Enhanced Dissolution of Silica and Alumina in Alkaline Environments. Langmuir, 35(48), 1565115660. https://doi.org/10.1021/acs.langmuir.9b02043

Elraies, A. K., Ahmed, F. A., Ayoub, A. M., \& Gaafar, R. G. (2016). An experimental investigation on the impact of brine composition on silica solubility at high temperature. International Journal of Mechanics, 12, 90-94.

Elraies, K. A., \& Kalwar, S. A. (2013). The Application of Acrylic Acid as Precipitation Inhibitor for ASP Flooding. Journal of Petroleum \& Environmental Biotechnology, 04(03), 4-7. https://doi.org/10.4172/2157-7463.1000141

Elraies, K. A., Tan, I. M., Fathaddin, M. T., \& Abo-jabal, A. (2011). Development of a New Polymeric Surfactant for Chemical Enhanced Oil Recovery. Petroleum Science and Technology, 29(14), 1521-1528. Retrieved from http://www.tandfonline.com/doi/full/10.1080/10916460903581427\#preview

Fatah, A., Ben Mahmud, H., Bennour, Z., Hossain, M., \& Gholami, R. (2021). Effect of supercritical CO2 treatment on physical properties and functional groups of shales. Fuel, 303, 121310. https://doi.org/10.1016/j.fuel.2021.121310

Fatah, A., Bennour, Z., Ben, H., Gholami, R., \& Hossain, M. (2021). Surface wettability alteration of shales exposed to CO2: Implication for long-term integrity of geological storage sites. International Journal of Greenhouse Gas Control, 110, 103426. https://doi.org/10.1016/j.ijggc.2021.103426

Fatah, A., Bennour, Z., Ben Mahmud, H., Gholami, R., \& Hossain, M. M. (2020). A Review on the Influence of CO2/Shale Interaction on Shale Properties: Implications of CCS in Shales. Energies, 13(12), 3200. https://doi.org/10.3390/en13123200

Gill, J. S. (1988). SILICA SCALE CONTROL. NACE, (226).

Ikeda, R., \& Ueda, A. (2017). Experimental field investigations of inhibitors for controlling silica scale in geothermal brine at the Sumikawa geothermal plant, Akita Prefecture, Japan. Geothermics, 70(April), 305-313. https://doi.org/10.1016/j.geothermics.2017.06.017

Iler, R. K. (1979). The Occurrence, Dissolution, and Deposition of Silica.

Jeirani, Z., Mohamed Jan, B., Si Ali, B., See, C. H., \& Saphanuchart, W. (2014). Pre-prepared Microemulsion Flooding in Enhanced Oil Recovery: A Review. Petroleum Science and Technology, 32(2), 180-193. Retrieved from 
http://www.tandfonline.com/doi/full/10.1080/10916466.2011.586968\#preview

Jing, G., Tang, S., \& Li, X. (2013). Analysis and Inhibition of Scale Accumulation for a Producing Well in the Daqing Oilfield. Petroleum Science and Technology, 31(17), 1772-1777. Retrieved from http://www.tandfonline.com/doi/full/10.1080/10916466.2011.631072\#preview

Kazempour, M., Sundstrom, E., \& Alvarado, V. (2012). Geochemical modeling and experimental evaluation of high-pH floods : Impact of Water - Rock interactions in sandstone. Fuel, 92(1), 216-230. https://doi.org/10.1016/j.fuel.2011.07.022

Lauren E. Beckingham. (2017). Evaluation of macroscopic porosity-permeability relationships in heterogeneous mineral dissolution and precipitation scenarios. Water Resour. Res., 53(12), 10217-10230. https://doi.org/https://doi.org/10.1002/2017WR021306

Li, J.-J., Jiang, H.-Q., Hou, J.-R., \& Wang, S.-L. (2014). The Effects of Oil Displacement Efficiency and Conformance Efficiency on Viscosity of ASP Flooding in a Heterogeneous Reservoir. Petroleum Science and Technology, 32(7), 830-839. Retrieved from http://www.tandfonline.com/doi/full/10.1080/10916466.2010.529548\#preview

Liu, Z., Bode, V., Hadayati, P., Onay, H., \& Sudhölter, E. J. R. (2020). Understanding the stability mechanism of silica nanoparticles: The effect of cations and EOR chemicals. Fuel, 280(May). https://doi.org/10.1016/j.fuel.2020.118650

Nguyen, T. B. N., Bae, W., \& Dang, T. Q. C. (2014). Improvements of Mixed-surfactants in Alkaline/Surfactant/Polymer Solutions. Petroleum Science and Technology, 32(12), 1458-1464. Retrieved from http://www.tandfonline.com/doi/full/10.1080/10916466.2012.669001\#preview

Niu, Q., \& Zhang, C. (2019). Permeability Prediction in Rocks Experiencing Mineral Precipitation and Dissolution: A Numerical Study. Water Resources Research, 55(4), 3107-3121. https://doi.org/10.1029/2018WR024174

Pratap, M., \& Gauma, M. S. (2004). Field Implementation of Alkaline-Surfactant-Polymer (ASP) Flooding : A Maiden Effort in India. SPE Asia Pacific Oil and Gas Conference and Exhibition, 88455. https://doi.org/10.2118/88455-MS

Sonne, J., Kerr, S., \& Miner, K. (2012). Application Of Silicate Scale Inhibitors For ASP Flooded Oilfields : A Novel Approach To Testing and Delivery. SPE 154332.

Sonne, J., Miner, K., \& Kerr, S. (2012). Potential For Inhibitor Squeeze Applicatio n For Silicate Scale Control In ASP Flood. SPE 155039.

Southwick, J. G. (1985). Solubility of Silica in Alkaline Solutions: Implications for Alkaline Flooding. SPE.

Steinwinder, J., \& Beckingham, L. E. (2019). Role of Pore and Pore-Throat Distributions in Controlling Permeability in Heterogeneous Mineral Dissolution and Precipitation Scenarios. Water Resources Research, 55(7), 5502-5517. https://doi.org/10.1029/2019WR024793

Swanson, B. F. (1981). A simple correlation between permeabilities and mercury capillary pressure. J. Petrol. Technol., 33, 2498-2504.

Tagavifar, M., Jang, S. H., Sharma, H., Wang, D., Chang, L. Y., Mohanty, K., \& Pope, G. A. (2018). Effect of pH on adsorption of anionic surfactants on limestone: Experimental study and surface complexation modeling. Colloids and Surfaces A: Physicochemical and Engineering Aspects, 538, 549-558. https://doi.org/10.1016/j.colsurfa.2017.11.050

Tan, Q., You, L., Kang, Y., Zhang, X., \& Meng, S. (2020). Changes in pore structures and porosity-permeability evolution of saline-lacustrine carbonate reservoir triggered by fresh water-rock reaction. Journal of Hydrology, 580, 124375. https://doi.org/10.1016/j.jhydrol.2019.124375

Yan, H.-Y., Xiao, M., Zhang, Z.-Z., Li, J.-Q., \& Shi, B.-Q. (2014). Remediation of Oilfield Wastewater Produced From Alkaline/Surfactant/Polymer Flooding by Using a Combination of Coagulation and Bioaugmentation. Petroleum Science and Technology, 32(13), 1521-1528. Retrieved from http://www.tandfonline.com/doi/full/10.1080/10916466.2012.685543\#preview

Yanaze, T., Yoo, S. Y., Marumo, K., \& Ueda, A. (2019). Prediction of permeability reduction due to silica scale deposition with a geochemical clogging model at Sumikawa Geothermal Power Plant. Geothermics, 79(August 2018), 114-128. https://doi.org/10.1016/j.geothermics.2019.01.002

Yupu, W., Junde, L., Bing, L., Yingping, L., Hongxing, W., \& Gang, C. (2004). Why Does Scale Form in ASP Flood? How to Prevent from It?--A Case Study of the Technology and Application of Scaling Mechanism and Inhibition in ASP Flood Pilot Area of N-1DX Block in Daqing. SPE 87469. https://doi.org/10.2523/87469-MS 